\title{
Interações entre veículos impressos e online: novos espaços para a comunicação política
}

\author{
Juliano Borges
}

\section{Resumo:}

O objetivo deste artigo é compreender, empiricamente, as interações entre jornais impressos e webjornais no âmbito da comunicação política. A análise do funcionamento dos veículos revela uma intensa relação entre os diferentes meios de comunicação, ora com incorporações de informações publicadas nos webjornais, ora com desprezo pelo que foi trazido na véspera pela versão «online». $\mathrm{O}$ trabalho investiga as motivações editoriais e esclarece os mecanismos técnico-profissionais que orientam a produção de notícias no contexto da interação entre meios de comunicação.

\section{Palavras Chave:}

internet, webjornalismo, comunicação política.

\begin{abstract}
:
The aim of this empirical article is to understand interactions between press journals and webjournals on political communication. The analysis of media working method reveals a intense relationship between then, sometimes incorporating information published by webjournals, sometimes discarding what have been published by online version. This paper investigates editorial motivations and clarifies technical procedures responsable for news prodution on the context of media interaction.
\end{abstract}

\section{Keywords:}

internet, webjournalism, political communication.

Desde a década de 90 que os primeiros cem dias de governo são um referencial adotado pela imprensa do Brasil como meio de acompanhar e avaliar as ações políticas do governo recém-empossado. Neste trabalho, no entanto, os cem dias de governo são utilizados como instrumento metodológico para compreender como o webjornalismo se comporta quando o ambiente político não está centralizado por um tema (como eleições presidenciais ou reformas constitucionais de grande alcance).

O advento das notícias em tempo real (NTRs) pelo webjornalismo ocasionou a adoção de rotinas de trabalho orientadas por uma temporalidade regular, marcada pela obrigatória redução máxima do tempo entre o acontecido e a publicação. A política, por sua vez, possui um tempo peculiar. Existem diferentes formas de expressão do tempo, mas há uma íntima relação entre o tempo da política - regido por temporalidades próprias da natureza dos seus diferentes conflitos - e o tempo da imprensa, em especial do webjornalismo, orientado pela radicalização do pressuposto da velocidade jornalística, consagrado pelo princípio do 'tempo real'. Diferenciadas em três formas distintas (restrita, aberta e semi-restrita), me deterei neste artigo apenas à temporalidade aberta.

Nos cem primeiros dias de governo, a cobertura está sempre relacionada ao cotidiano da política. Ela opera segundo uma temporalidade aberta porque os objetivos e movimentos políticos não estão pré-condicionados a uma agenda dada - como em processos eleitorais, regidos por temporalidade restrita; ou processos decisórios legislativos não-eleitorais, regidos por temporalidade semi-restrita (BORGES, 2007). A necessidade de operar no cotidiano da política possibilita mais opções de pauta, uma vez que o veículo não está atrelado à 
necessidade de cobertura de um evento cuja importância é estabelecida de antemão pelo contexto político. Assim, na temporalidade aberta, o jornalismo político tem ampla margem de seleção sobre o que será conhecido, reagindo aos fatos e contribuindo ativamente para provocar imagens, elaborar sentidos, contribuir, enfim, no processo que de construção do mundo social.

Fora os eventos de grande repercussão, sempre noticiados por quaisquer meios de comunicação, ocorrem fatos que podem ou não ser publicados, e que, se publicados, podem receber tratamentos diferenciados, segundo um conjunto de fatores: linha editorial da empresa, vínculo com outros fatos publicados pelo jornal e espaço físico destinado à publicação. Há, portanto, um poder de publicidade cujo emprego depende de combinações de escolhas do jornal. Nos jornais impressos, em que o espaço de publicação é mais limitado do que no «online», uma quantidade maior de fatos é ignorada pela cobertura política. Ou seja, há um volume de informação desprezado, não inserido na comunicação política. A escolha dos cem primeiros dias de governo como caso de estudo deste artigo pretende compreender, empiricamente, o comportamento dos webjornais tendo como foco de análise as interações entre jornais impressos e webjornais. Enfoque, extensão da cobertura e personagens mobilizados para dar conta do mesmo fato, em outro meio de comunicação, são elementos observados para compreender como eles aparecem quando há outro veículo a ser comparado. Refiro-me à incorporação de informações publicadas nos webjornais em notícias impressas ou, ao contrário, ao desprezo das informações trazidas na véspera pela versão «online». Avaliarei que tipo de informação é aproveitada/publicada nos jornais impressos, se apenas as de grande relevância ou se também relacionadas com notícias de menor impacto político. Adiante, busco identificar uma marca editorial capaz de distinguir as NTRs das notícias publicadas nos impressos; as motivações que levam ao aproveitamento de notícias; e o grau de sinergia entre as duas versões, «online» e impressa.

\section{Metodologia de pesquisa}

A pesquisa foi baseada na composição de um sistemático banco de dados, constituído por amostras de exemplares dos jornais «O Globo», «Jornal do Brasil» e suas versões «online» a partir de uma metodologia de coleta. No caso dos jornais impressos, foram recolhidas todas as edições de terça-feira, quinta-feira e domingo, no período compreendido entre 2 de janeiro e 17 de abril de 2003. A opção pelas terças e quintas levou em conta a cobertura de dois momentos diferentes da semana, quando os movimentos políticos e os acontecimentos encontram-se em franco processo de desenvolvimento. São edições com forte caráter factual. O domingo foi escolhido por apresentar uma lógica editorial diferenciada dos demais dias da semana: mais analítica e menos factual. As edições de domingo escapam do formato cotidiano, assemelhando-se mais a uma revista. Os dois modelos correntes no jornalismo impresso diário (factual e de ênfase analítica) foram contemplados pela pesquisa.

Quanto ao«JB Online» e «O Globo Online», as notícias em tempo real foram o foco principal de estudo, por serem traço distintivo entre os dois tipos de veículo. Constantemente atualizadas, não haveria como apreender 'a' edição do dia das NTRs, posto que ela está sempre em constante processo de atualização. Considerando que, às 23:59 horas, a página de plantão era apagada, iniciando à meia-noite uma nova série de publicações, este passou a ser o horário-limite para o arquivamento da página. Meses depois de findada a pesquisa, com o reforço dos servidores e da infra-estrutura dos webjornais, as NTRs passaram a permanecer na internet por mais de 24 horas. Àquela altura, no entanto, visando conferir padronização ao material armazenado, estabeleci uma faixa de horário - entre 21 e 22 horas - que teria prioridade no salvamento, sem prejuízo para o banco de dados quando salvadas depois.

Para a análise do processo de enquadramento editorial e o utilização de NTRs pelos jornais impressos, foi necessário, ainda, o recolhimento de edições impressas dos dias seguintes ao salvamento de «JB Online» e «O Globo Online». A possibilidade de confrontação dos mesmos fatos, nas duas versões dos jornais, introduziu um componente enriquecedor para a análise, ao proporcionar um mesmo parâmetro noticioso para o 
comportamento dos dois modelos de jornalismo analisados. Com isso, depois de nova análise das edições impressas adquiridas, foi possível avaliar processos de conversão de NTRs em notícias convencionais e suas implicações. O arquivamento produziu, dessa maneira, um banco de dados com 92 amostras de jornais impressos e 46 'edições' «online» salvas ao longo de 16 semanas, sobre o qual me baseio para analisar aspectos próprios do webjornalismo.

\section{Interações entre o meio digital e o impresso}

Os webjornais nascem como transposição de um jornal impresso para a internet. Assim, é razoável que o jornalismo «online» guarde características de seu produto de origem. Porém, as empresas logo perceberam o potencial do novo meio de comunicação e passaram a explorar suas características, desenvolvendo uma nova forma de jornalismo, com redações próprias, estilo de texto adequado à internet, explorando a possibilidade de rápida publicação de notícias, bem como a ausência de limites espaciais para abrigá-las. Aos poucos, é o jornal impresso que passa a se alimentar do webjornalismo, estabelecendo uma interação mais profunda e equilibrada entre os dois meios. A empresa otimiza procedimentos de apuração de pautas, que podem servir a ambos os jornais. Mas essas pautas são desenvolvidas de maneiras diferentes e com premissas distintas. Dessa forma, a versão online ofereceria rapidez enquanto a impressa traria maior profundidade na abordagem, podendo desenvolver as notícias trazidas na véspera pelo webjornal.

Nos jornais «online», a restrição em publicar está mais associada à limitação do próprio corpo redatorial em abastecer o veículo do que no suporte tecnológico disponível. O limite de publicação encontra limitações humanas no processo de seleção dos fenômenos cotidianos e sua conversão em notícias. A atividade jornalística apreende, reorganiza e difunde as ações e os discursos produzidos socialmente, conferindo-lhes a credibilidade de uma mediação crítica. Portando esse entendimento de sua atividade, o jornalista assume o papel de interlocutor social, elaborando significados e construindo sentidos a partir da seleção de fenômenos cotidianos. Mas esta seleção, na rotina de produção da notícia, sofre constrangimentos de toda ordem - de espaço físico, político, profissional, ideológico, editorial e de mercado, não raro indiferenciáveis.

Sobre a influência do mercado na produção de notícias, Habermas lembra que "a troca de informações desenvolve-se não só em relação às necessidades do intercâmbio de mercadorias: as próprias notícias tornamse mercadorias. Por isso, o processo de informação profissional está sujeito às mesmas leis do mercado, a cujo surgimento elas devem, sobretudo, a sua existência" (HABERMAS, 1984: 34). Por esta lógica, um fato só será noticiado se tiver algum interesse comercial. O lucro, em geral, se reflete no grau de interesse do público leitor, que comprará o jornal de acordo com a capacidade de sedução das notícias anunciadas.

O caso é que os webjornais não estabelecem a mesma relação com anunciantes e com as notícias. Se os jornais impressos vendem anúncios (MEDINA, 1986), os webjornais vendem também velocidade. No webjornalismo, a sedução do leitor está mais em responder com velocidade aos fatos do que ser eficiente na seleção dos fenômenos que acontecem no dia-a-dia. Seleção e dinamismo são traços comuns a ambas as formas de jornalismo, variando sua ênfase. Enquanto a prioridade dos jornais impressos é a seleção dos fatos, nos webjornais a prioridade é o rápido abastecimento.

O funcionamento influenciado por marcas da cibercultura (flexibilidade e aceleração de fluxos de informação) garante um perfil diferente aos profissionais e à forma com que compreendem seu trabalho. A idéia de mediador crítico da sociedade é relativa, menos arraigada do que seus pares do jornalismo impresso, que tendem a pensar em si mesmos como organizadores dos discursos (TRAVANCAS, 1996). No jornal impresso, a seleção do fato, para poder convertê-lo em notícia (acontecimento jornalístico), deve negociar com limitações de espaço físico e constrangimentos políticos, profissionais, editoriais e de mercado para proceder à seleção. Na produção dos webjornais, para bem atender ao seu maior pressuposto, a velocidade, não pode transigir com os mesmos impedimentos, sob pena de não atingir seu principal objetivo. Ora, isso 
altera o caráter político do jornalismo, colocando problemas que estão mais relacionados à lógica de funcionamento - sua estrutura, e que não estão somente vinculados a interesses imediatos de mercado. Organizado sob uma estrutura empresarial, os webjornais, ironicamente, devem atentar menos para limitações de mercado, caso pretendam cumprir seu pressuposto e serem bem-sucedidos em sua atividade: prover notícias em "tempo real". Como parte relevante do complexo de empreendimentos e iniciativas que acontecem na internet, os webjornais parecem traduzir alguns paradoxos da rede. Eles são, ao mesmo tempo, um braço dos meios de comunicação de massa atuando na internet, com todos seus valores e interesses políticos, mas, nem por isso, deixam de ser influenciados pelas contradições políticas e disputas de hegemonia em curso na rede. Ao se diferenciar dos demais meios de comunicação pela radicalização do pressuposto jornalístico da velocidade, os jornais «online» flexibilizam outros fundamentos da atividade, como a seleção. O impacto disso é a entrada de personagens e cenários não contemplados por outras formas mais seletivas - de produzir notícia. Quando seleciona, o jornalismo impresso precisa excluir; quando precisa responder rapidamente aos fenômenos, o webjornalismo necessita incorporar.

Isto posto, o estudo dos quatro jornais analisados mostrou que há dois comportamentos básicos envolvendo a interação entre os meios impresso e digital:

\section{NTRs aproveitadas:}

Dá-se quando um acontecimento é publicado no jornal «online»e, no dia seguinte, é noticiado, desenvolvido ou não, no jornal impresso, em um processo de transmissão regular da informação. Entretanto, a publicação de um fato, na edição do dia seguinte, não impede que haja diferenças de enquadramento, quando, apesar da manutenção da notícia, ocorre intervenção editorial.

2. NTRs não aproveitadas:

As NTRs não são aproveitadas quando uma informação publicada pelo webjornal não é noticiada na versão impressa. As razões para isso relacionam-se com limitações espaciais e motivações editoriais, como a prioridade de publicação na internet para outros fatos.

Passo então à análise da interação entre as versões, observando as formas com que NTRs conectam-se à produção da notícia nos jornais impressos.

\section{Notícias impressas relacionadas com NTRs}

Boa parte das notícias publicadas pelos jornais impressos tem relação com notícias vistas na versão «online» do jornal na véspera. No caso do JB, elas são a maioria das notícias publicadas pelo jornal (113 NTRs em 205 notícias impressas, isto é 55,12\%), mas o mesmo não ocorre com «O Globo» (242 em 692, ou 34,12\% de notícias aproveitadas).

O aproveitamento de NTRs está relacionado ao tipo de trabalho das redações. Nos webjornais, elas funcionam com equipes pequenas que dependem, em grande medida, do trabalho realizado por repórteres das versões impressas. Eles enviam, do local do fato, informações que serão convertidas em NTRs pelos webjornalistas. A apuração do acontecimento publicado em primeira mão no webjornal é feita, portanto, por quem redigirá mais tarde a notícia para o jornal impresso. Com as informações preliminares passadas à redação, cabe aos repórteres do «online» apurar mais detalhes e explorar fontes alternativas, mobilizando outros meios telefone, principalmente, e a própria internet - para complementar a apuração, enriquecendo-a com mais informações e novos pontos de vista. Boa parte das notícias de um jornal é produto de decisões de pautas tomadas anteriormente. Se o processo de produção de NTRs tem início com a seleção de pautas e sua cobertura por jornalistas do impresso, é compreensível que um número significativo das NTRs seja 
aproveitado para publicação impressa. Portanto, quanto menores forem as opções de cobertura e menor a quantidade de pautas apuradas, maiores serão os índices de aproveitamento da notícia na edição impressa, pois menores serão as alternativas dispostas pela empresa para dar conta da diversidade de fatos que acontecem durante um dia.

Isto explica o porquê do alto índice de NTRs aproveitadas no JB em relação ao seu concorrente carioca. $\mathrm{O}$ «O Globo Online» possui uma equipe de repórteres maior e mais habituada à saída da redação. Isto proporciona ao jornal maiores diferenças em relação à sua versão impressa, pois ocorrem mais casos em que o repórter que apura a matéria não é o mesmo que escreve para o jornal impresso. Além disso, "Globo Online» conta com grande quantidade de agências de notícias contratadas em outras cidades, além de uma sucursal «online» em Brasília e outra em São Paulo (enquanto o «JB», por sua vez, só dispunha de um único repórter em cada uma dessas cidades).

Essas podem ser as razões pelas quais «O Globo» publicou 26,02\% de notícias sem relação alguma com NTRs de sua versão «online», enquanto o Jornal do Brasil apresentou um volume maior, de 35,60\%. Ou seja, o JB Online depende mais do trabalho de apuração preliminar realizado por sua versão impressa, enquanto «O Globo Online», ainda que não completamente independente, apresenta maior autonomia em relação a $\mathrm{O}$ Globo.

Esta seção dá subsídios para tratar da autonomia das versões online diante do funcionamento dos jornais impressos, que serve à discussão a seguir, sobre pautas e NTRs não utilizadas. Se os webjornais, a despeito de pertencerem à mesma empresa, dispõem de maior liberdade de funcionamento, é possível supor que quanto maior a autonomia de trabalho das equipes do online mais freqüentes serão os casos em que haverá divergência entre a linha editorial da empresa e o perfil político das NTRs publicadas.

\section{NTRs não utilizadas}

A análise das pautas desprezadas pelos jornais mostra que há um número considerável de NTRs não aproveitadas. No caso do JB, mais de um quarto das notícias trazidas na versão online foram ignoradas $(26,35 \%)$ e, no caso de «O Globo», um volume de mais de um terço das NTRs trazidas pela versão «online» $(39,11 \%)$ foi desprezado.

Dois motivos explicam esse fenômeno. NTRs são desprezadas porque divergem da linha editorial dos jornais impressos (razões profissionais). Se as redações do webjornalismo dispõem de maior liberdade de produção, pelo ganho de autonomia relativa do repórter diante do controle exercido por editores, é plausível que haja um número maior de notícias que escapam da uniformização exercida pela linha editorial. O sentido político da notícia é diferente. Assim, no processo de seleção de notícias pelo jornal, pautas e NTRs inadequadas à linha editorial são excluídas.

A segunda razão indica que características próprias do webjornalismo motivam pautas e NTRs que não servem ao jornalismo impresso e por isso são desprezadas. Ao contrário da primeira explicação, que aposta em motivações editoriais, como a posição da empresa diante de uma hegemonia política, sempre sujeita à mudança, a segunda, ainda que complementar à primeira, admite um fundo explicativo de ordem técnica. Isto é, independentemente dos interesses permanentes ou transitórios de uma ou outra empresa, o jornalismo na internet opera com um conjunto de informações que não servem para o jornalismo impresso. Mais do que isso, ocorre uma diferença de entendimento do que seja notícia nos dois meios de comunicação. Os jornais online trabalham com a publicação de ocorrências políticas, tais como elas são, enquanto, para os jornais impressos, que operam com um dia de diferença em relação aos acontecimentos, este tipo de notícia se destitui de qualquer conteúdo político e interesse jornalístico. Por exemplo, a NTR publicada no dia 25 de fevereiro, às 12:45h, pelo «JB Online», 'Bancada do PT reunida para indicar integrantes das comissões' 
destaca as principais lideranças cotadas para as várias comissões do Parlamento e as chances de cada nome, segundo os grupos políticos no interior do partido. Para o «JB Online» esta notícia confere ao veículo credibilidade no meio jornalístico e perante a opinião pública, seja por ativar o princípio da velocidade de cobertura, seja pela sensação de ubiqüidade que proporciona ao seu leitor no acompanhamento dos eventos políticos. Ao mesmo tempo, ela reforça a distinção entre jornais online e impressos. Para o jornal impresso, por outro lado, a publicação de semelhante notícia só se justificaria, por exemplo, se houvesse algum fato inesperado no resultado da escolha dos integrantes, pois não é comum a esses veículos cobrir detalhadamente movimentos partidários no Congresso. Eventualmente, edições de domingo dos jornais impressos dedicam alguma atenção a cenários partidários, sem, contudo, apresentar a referência factual que a cobertura online sempre traz. Esta é uma marca deste tipo de jornalismo, que aprofunda a relação entre um evento e sua localização espaço-temporal.

Os perfis da notícia podem ser conflitantes com a linha editorial da empresa, mas não há como garantir que se houvesse mais espaço de publicação nos jornais impressos todas elas seriam ignoradas apenas pela divergência editorial. Como também não é possível assegurar que apenas o rigor da linha editorial impeça a publicação de NTRs com conteúdo político inadequado ao jornal impresso. Afinal, constrangimentos técnicos também proporcionam cortes. Fatores técnicos e profissionais estão, portanto, interrelacionados e assim precisam ser abordados.

Existem notícias que são típicas do jornalismo político produzido pelos webjornais. Há uma forte ênfase em NTRs relacionadas à agenda política. Considerando a limitação espacial dos jornais impressos, a necessidade de seleção dos editores e, sobretudo, o caráter particularmente efêmero de NTRs relacionadas à agenda política, as notícias desta subeditoria tornam-se mais suscetíveis a não serem aproveitadas pelos jornais impressos. Estou tratando, em grande medida, do que identifico neste trabalho como uma ocorrência política, isto é, informações relativas a uma agenda social da política e ao seu cotidiano extra-oficial. Do ponto de vista da comunicação política, uma informação, trazida a público sob a forma mera de ocorrência, tem baixa relevância.

\section{Mudança de enfoque}

O estudo das notícias publicadas por «Jornal do Brasil», «O Globo», e suas versões na internet aponta para freqüentes mudanças de enfoque, isto é, um mesmo fato, coberto pelas duas modalidades de jornal, da mesma empresa, apresenta diferenças significativas quanto à produção do sentido da notícia. A pesquisa demonstra que essas mudanças podem ocorrer de três formas.

O primeiro tipo de mudança de enfoque tem relação com fatores exógenos. Neste caso, é o desenvolvimento dos fatos que modifica a expectativa da cobertura para aquela pauta, mudança geralmente causada por imprevistos que fazem o evento perder interesse noticioso. No segundo tipo de mudança de enfoque, um fato é noticiado pelo jornal impresso sem que todas informações publicadas no dia anterior pela versão «online» sejam inseridas na matéria. Isto acarreta mudanças no significado político da notícia, aumentando ou atenuando seu viés ideológico. No terceiro tipo, fatores endógenos às formas de produção da notícia (intervenção editorial) redirecionam o enfoque, adequando-o à linha editorial da empresa. A adaptação do fato à política editorial significa a inserção de informações não publicadas pelos webjornais, o que modifica o contexto sobre o qual o fato havia sido apresentado na véspera.

A pesquisa de todas as notícias coletadas no período dos cem primeiros dias do governo Lula, confrontando«JB»e «JB Online», «O Globo» e «O Globo Online», encontrou 46 casos de mudanças de enfoque. Devido à reduzida disponibilidade de espaço, passo a uma breve análise de casos selecionados para esclarecer como funciona a interação entre os meios e o que ela pode produzir. 
Razões associadas a fatores externos à redação e a motivações editoriais podem modificar o enfoque noticioso. Neste caso, o desenlace da pauta não produz um fato de interesse jornalístico. Esta mudança de expectativas geralmente é causada por imprevistos e faz com que o evento perca interesse noticioso. Dessa maneira, o fato, que havia recebido grande atenção dos webjornais no dia anterior, não chega a ser importante o bastante para ser publicado da forma planejada, dispensando informações que se tornam irrelevantes para a cobertura. Em relação aos demais casos de mudança de enfoque, estes ocorrem em menor número. Foi detectado um padrão semelhante de comportamento dos jornais impressos, em relação às suas versões na internet, quando a mudança de enfoque ocorre por alteração dos acontecimentos na véspera. $\mathrm{O}$ desenvolvimento do fato é acompanhado atentamente pelo jornal «online» por meio de um conjunto de NTRs. No entanto, a mudança nos rumos do evento impede que o jornal impresso utilize as informações apuradas na véspera. Nestes casos, não faz sentido para o jornal impresso a publicação das idas e vindas de um fato que, frustrado em seu desenvolvimento, perde atrativo jornalístico. Diante da alteração da pauta prevista, as versões impressas produzem matérias com abordagem mais ampla, perfil menos factual, e reforço no sentido político do tema.

\section{NTRs não incorporadas}

Uma das principais formas verificadas de mudança de enfoque pelos jornais impressos acontece pela não incorporação de personagens valorizados em NTRs da véspera. Na produção da versão impressa, a exclusão de atores políticos leva consigo seus discursos, noticiados no entanto pelos webjornais. Com isto, a notícia impressa perde um importante componente político e o fato torna-se mais sujeito a ser enfocado de forma distinta do «online». A atenção à linha editorial do jornal ou ao princípio da objetividade jornalística leva à exclusão de determinados atores. Isto significa que suas opiniões deixam de ser contempladas pela comunicação política, o que possibilita a mudança do enfoque da notícia.

A propósito da tentativa do governo Lula de trazer o PMDB para a base aliada, o JB Online publicou em 25 de fevereiro de 2003 uma NTR tendo como personagem o senador pelo estado da Paraíba José Maranhão sobre as condições para a entrada do partido no governo ('Maranhão avisa: PMDB não aceita nada abaixo do primeiro escalão' (1)). No dia seguinte, a única notícia publicada pelo JB sobre o tema teve uma abordagem completamente distinta ('Temer diz que PMDB não quer cargos para apoiar reformas. Presidente do partido critica fisiologismo mas admite participar do governo' (2)). A versão impressa não somente ignorou a notícia publicada pelo «JB Online»; ela preferiu abordar o mesmo fato sob um ponto de vista totalmente diferente. Trata-se de mais um caso em que a não incorporação de um ator político noticiado pela versão online alterou não somente o enfoque da notícia como também seu sentido político. A divisão interna do PMDB se traduz em posições políticas diferentes dentro do mesmo partido, de acordo com o grupo em questão (nordestino, paulista, autêntico, independente etc). A opção editorial dos jornais por um desses grupos, sem contemplar outros, significa dar ao partido uma unidade de discurso político que ele não possui. No caso do PMDB, permeado por grupos com pontos de vista e interesses políticos divergentes, o JB, ao construir sua matéria sobre a participação do PMDB no governo, não incorporou as informações apuradas na véspera e publicadas pelo JB Online. Isto determinou uma diferença de sentidos sobre o assunto. O primeiro enfoque caracteriza o PMDB como partido fisiológico. O segundo apresenta um discurso diferente, preocupado em se afastar do fisiologismo. Não há como determinar os motivos que levaram à exclusão da fala de José Maranhão. Mas a opção reduziu a variedade de discursos políticos sobre o assunto, empobrecendo a discussão. Os exemplos mais importantes de mudança de enfoque pela não incorporação de NTRs na cobertura do Jornal do Brasil ocorreram com a exclusão de determinados atores. Isto significou um viés diferente para o fato abordado, com mudança do sentido da notícia em alguns casos, e a perda de força política dos discursos excluídos na comunicação política dos jornais impressos. 
A interação dos jornais «O Globo» e «O Globo Online» também produziu exemplos relevantes neste tipo de mudança de enfoque. Um caso emblemático ocorreu no dia 2 de janeiro de 2003, quando o webjornal publicou um conjunto de NTRs sobre o estado do Espírito Santo e o recém-empossado governador Paulo Hartung. Motivada pelo crescimento das estatísticas de criminalidade, a Secretaria de Segurança Pública do Ministério da Justiça tinha a intenção de começar a implantação do Sistema Único de Segurança Pública pelo Espírito Santo, fato noticiado pela versão online ('Integração da PF com polícias estaduais começa pelo Espírito Santo'(3)). Outra pauta bastante explorada pelo jornal na Internet foi o acordo tentado por Hartung para liberar, junto ao governo federal, um montante destinado ao pagamento do funcionalismo capixaba, que acumulava três meses de atraso na ocasião ('Hartung busca liberação de R\$ 300 milhões para pagar funcionalismo' (4), 'Lula repassa a Palocci pedidos do governador do Espírito Santo' (5) e 'Governador diz que $50 \%$ das verbas enviadas para o ES foram desviados'(6)). No dia seguinte, a notícia relativa ao fato publicada por O Globo trouxe um ponto de vista bastante diferente sobre o tema ('Hartung pede a Lula que libere verba para pagar funcionalismo. Governador diz que presidente prometeu dinheiro. Singer nega' (7)).

Comparando o conjunto de notícias publicadas na véspera com a matéria do dia seguinte percebe-se uma diferença não somente no raio de cobertura, como também na abordagem do tema. Não houve informações sobre a integração da Polícia Federal com as polícias estaduais, apesar do ensejo proporcionado pela notícia, que já tratava do Espírito Santo. Também não houve informações sobre os $50 \%$ de verbas desviadas, motivo que, segundo o governo do estado, explicaria o atraso nos pagamentos do funcionalismo. O porta-voz da Presidência tampouco aparece nas notas do jornal «online». As notícias NTRs têm enfoque favorável ao governador do Espírito Santo, informando sobre a atenção especial que receberia o estado na área de segurança pública, justificando o atraso no pagamento dos servidores estaduais, e demonstrando o esforço do governo para resolver o problema. Na versão impressa, no entanto, a exclusão de informações publicadas por «O Globo Online» confere um sentido negativo ao texto. Ao publicar a afirmação de Hartung sobre a liberação da verba pelo governo federal, contradizendo o primeiro com a negativa de um representante do segundo, o jornal desqualifica o governador. A não incorporação de informações apuradas pela equipe de reportagem do jornal, só veiculadas por «O Globo Online», alterou o sentido original, tornando-o desfavorável ao personagem principal da matéria.

Esta seção demonstrou que uma das formas de mudança de enfoque se dá quando jornais impressos não incorporam informações apuradas e publicadas na véspera na forma de NTRs. Entender como se dá a interação entre os meios impresso e digital, neste caso, envolve reconhecer a influência de duas instâncias que atuam na produção de notícias: as características técnicas de funcionamento de um jornal, e a atuação de seus profissionais - editores e redatores - no processo de produção da notícia em um determinado meio de comunicação. São duas instâncias interrelacionadas e mutuamente influenciadas, cujos limites de atuação são difíceis de se definir.

A relação entre a dinâmica de trabalho própria das redações «online», em que importa o respeito à linha editorial, por um lado, e certo grau de autonomia dos webjornalistas, por outro, relaciona-se com o grau de velocidade de produção da notícia, processos contínuos de atualização do veículo e sua capacidade ampliada de publicação. As rotinas de trabalho que determinam o comportamento dos jornalistas são portanto influenciadas por características do meio digital. Estas características técnicas, no entanto, não definem por si mesmas o modelo de webjornalismo. São profissionais que decidem como as potencialidades técnicas da internet são aplicadas a um tipo de jornalismo produzido na rede. Não há um determinismo tecnológico na configuração do webjornalismo, que admite outros modelos de produção da notícia. A relação profunda entre instâncias técnica e profissional influencia o tipo de comunicação produzida, qualquer que seja o meio, e na Internet não é diferente.

Uma vez que os jornais impressos, à sua maneira, também precisam lidar com esta relação entre o meio técnico e o comportamento humano, a interação desse modelo de jornalismo com o produzido pelos jornais 
«online», que funciona com outros pressupostos, motiva processos interessantes de adequação da informação.

A não incorporação de informações elaboradas na véspera é uma das formas de interação que provoca mudanças no enfoque de um o fato. Atentos à velocidade acelerada de produção e atualização, os webjornais publicam freqüentemente NTRs que não servem ao modelo técnico-editorial dos jornais impressos. Assim, uma notícia com perfil bombástico, impulsivo ou imediatista (cuja informação está referida ao tempo presente) tende a ser valorizada pelos jornais na internet, mas costuma ser desprezadas pela versão impressa. Nem sempre é possível afirmar os motivos da não incorporação da informação. Em certos casos, a linha editorial indica o corte. Declarações agressivas ou extremadas podem não se adequar à política editorial do jornal impresso, mesmo que respaldadas pelo webjornal. Em outros casos, são motivos técnicos que determinam que a informação não seja aproveitada. Se ela está excessivamente relacionada a uma circunstância do tempo presente, o jornal impresso pode perder o interesse pela publicação de um fato dessa natureza no dia seguinte. Há, entretanto, uma série de casos cujos motivos de não incorporação são mais subjetivos e não há como precisar se o corte está ligado a interesses políticos (dimensão profissional), à falta de espaço físico na edição (dimensão técnica) ou, ainda, a convergência das duas motivações.

O estudo dos casos apresentados nos permite algumas considerações. Os jornais impressos tendem a não incorporar declarações intempestivas ou extremadas, optando por uma linha de moderação. Não há quaisquer indícios que indiquem motivações políticas para este tipo de corte. A Internet é marcada por certo grau de informalidade na comunicação e isto também influencia o produto dos webjornais. Em comparação, os jornais impressos tendem a ser mais conservadores na seleção das falas (como algo é dito). Neste caso, a não incorporação de certas falas pode estar mais associada ao tipo da notícia apropriada para cada meio (adequação ao perfil do jornal) do que ao controle sobre o conteúdo da fala (o que é dito).

Outra forma identificada de mudança de enfoque motivada pela não incorporação de NTRs é a exclusão de determinados personagens políticos na produção da notícia. Isto implica em conseqüências mais importantes para o conteúdo do que é publicado porque freqüentemente a exclusão de atores políticos retira a presença do contraditório na notícia. Nestes casos, mais do que a mudança de enfoque, há alteração do sentido das informações publicadas sobre um fato. Ao optar por certos personagens para narrar um evento, em detrimento de outros personagens ouvidos e publicados pela empresa, o jornal impresso perde a oportunidade de confrontar pontos de vista e contribuir para ser aquilo que o senso comum costuma sustentar: um espaço jornalístico mais crítico e reflexivo. Quando o processo de seleção da informação não incorpora atores políticos, seja por razões editoriais ou por motivos técnicos, o jornal abre mão de falas e discursos, empobrecendo a comunicação política. Como visto, nos casos de exclusão de atores, prevaleceu um discurso com sentido diferente do publicado pelo webjornal, sem que fossem incorporadas no entanto outras perspectivas para o mesmo fato. Neste sentido, a despeito da crítica à velocidade de procedimentos na produção da notícia, os webjornais contribuem para trazer atores e discursos que os impressos nem sempre contemplam, aumentando assim o grau de diversidade de visões sobre um mesmo fato na comunicação com o público leitor.

\section{Incorporação de NTRs com mudança na forma de apresentação}

Uma segunda forma de alteração de enfoque jornalístico na interação das versões impressa e «online» se dá pela incorporação de informações apuradas e publicadas na véspera, pelo webjornal, com apresentação, porém, em um contexto diferente, seja pela inserção em meio a outras notícias de perfil diferente, seja pela própria elaboração do conteúdo do texto jornalístico. Apresento dois exemplos significativos que demonstram esta forma de mudança de enfoque.

Na edição do «JB Online» do dia 14 de janeiro, o então presidente da Argentina, Eduardo Duhalde, foi pauta de NTR sobre as discussões em torno da aproximação com o Brasil, o fortalecimento do Mercosul e as 
políticas públicas comuns. Na matéria, que aborda o encontro dos presidentes dos dois países em Brasília, o argentino elogia 'a liderança do Brasil' e de Lula no continente ('Duhalde: união está no 'código genético' de Brasil e Argentina' (8). A notícia é francamente favorável à aproximação entre os dois países e, em especial, ao presidente do Brasil.

A edição do dia seguinte, no entanto, tem enfoque diferente, apesar da cobertura do mesmo evento e de trazer no texto as mesmas declarações de Duhalde publicadas pelo webjornal na véspera. A manchete em primeira página, acompanhada de uma foto dos dois presidentes, remete a uma pequena notícia no interior do jornal, desproporcional ao destaque da chamada em primeira página ('Lula e Duhalde discutem Mercosul.

Presidentes acertam priorizar área social' (9). No online, o foco principal é Duhalde e a união entre Brasil e Argentina. No impresso, a cobertura menciona a defesa por Duhalde da união Brasil-Argentina, mas o foco principal é sua crítica ao modelo econômico adotado pelos países latino-americanos. Na matéria, a defesa de união entre os países é feita por Lula, que é o personagem principal da notícia. Embora assinadas pelo mesmo jornalista, Luis Osvaldo Grossman, as matérias publicadas pelo «JB Online» e pelo «Jornal do Brasil» têm abordagens diferentes sobre o mesmo assunto, o que conota intervenções editoriais.

No jornal «O Globo» ocorreram nove situações de mudança de enfoque com reaproveitamento de informações. Cito, no entanto, apenas a mais relevante.

A cobertura da posse do gabinete de Lula promovida pelos jornais na Internet em 2 de janeiro destacou cada um dos Ministérios. No caso das Comunicações, «O Globo Online» conferiu sentido positivo à notícia, destacando o otimismo do ministro empossado, Miro Teixeira, do Partido Democrático Trabalhista, legenda que apoiou Lula no segundo turno das eleições ('Miro: 'Espero não decepcionar o meu partido, o PDT, o presidente Lula e o povo brasileiro" (10). A versão impressa, ainda que preservando as declarações de Miro no corpo da matéria, tem outro enfoque: 'Miro assume sem presença de Brizola. O ministério é que tomará as decisões políticas, não a Anatel, diz ele' (11). A perspectiva de «O Globo» explora o conflito político de Miro tanto com seu partido quanto com a Agência Nacional de Telecomunicações; o tom da NTR é mais leve e mais favorável a Miro Teixeira e ao próprio governo.

Este caso, como outros encontrados pela pesquisa, ilustra algumas características da notícia nos webjornais. Elas são mais diretas, radicalizando o princípio da objetividade jornalística. A flexibilidade das rotinas e a autonomia relativa dos repórteres do «online» proporcionam uma interferência menos acentuada das linhas editoriais da empresa. A leveza e objetividade do texto e até mesmo um grau de autonomia relativa de repórteres diante do corpo editorial é construída não somente por exigências técnicas, ainda que elas tenham importância. Há também fatores relacionados ao perfil profissional do jornalista do «online» que precisam ser compreendidos.

\section{Considerações finais}

$\mathrm{O}$ artigo apresenta algumas das diferenças entre jornais impressos e «online». No entanto, alguns outros fatores de distinção devem ser considerados se quisermos compreender como veículos de uma mesma empresa apresentam resultados tecnicamente e editorialmente diferentes. A influência de traços da cibercultura, por exemplo, e a construção de uma forma própria de se fazer jornalismo, a partir da formação e dos valores próprios de webjornalistas, devem ser entendidas como elementos que determinam como a informação é recepcionada e elaborada nas redações do online. Isto significa que não somente aspectos técnicos, como a capacidade ampliada de publicação e a possibilidade de atualização constante de webjornais, definem o caráter das NTRs. Existem elementos de natureza profissional que também são relevantes para o resultado do trabalho dos webjornais, ainda que os limites entre a técnica e as motivações meramente humanas sejam difíceis de serem precisamente definidos. 
Mesmo pela perspectiva das linhas editoriais, a diferença de pautas e de como elas são desenvolvidas não é fruto apenas de determinantes técnicos. Levando em consideração o perfil do público-leitor da internet, à empresa pode interessar utilizar seu webjornal como um meio de se expor de forma mais leve, mais liberal e menos "editorializada" para a opinião pública. Assim, características como o equilíbrio editorial, a entonação do texto nos webjornais e a utilização de fontes diferentes dos jornais impressos não podem ser explicadas somente como resultado de determinações tecnológicas. Elas estão sujeitas também à forma como os webjornalistas recepcionam a informação e a elaboram. Essas características são produto, também, da influência direta do perfil desses novos profissionais da imprensa.

\section{Bibliografia:}

BORGES, Juliano. Política e jornalismo em tempo real. Webjornalismo e novos espaços de cobertura política. Tese de doutoramento defendida no Instituto Universitário de Pesquisas do Rio de Janeiro (IUPERJ).

HABERMAS, Jürgen. Mudança estrutural na esfera pública. Rio de Janeiro: Tempo Brasileiro, 1984.

MEDINA, Cremilda. Notícia: um produto à venda. Jornalismo na sociedade urbana e industrial. São Paulo: Summus, 1986.

TRAVANCAS, Isabel. O mundo dos jornalistas. São Paulo: Summus, 1993.

\section{Notícias}

JB ONLINE. 'Duhalde: união está no código genético de Brasil e Argentina'. www.jb.com.br. Publicado em 14.01.2003, às 16:30h.

JB ONLINE. 'Maranhão avisa: PMDB não aceita nada abaixo do primeiro escalão'. www.jb.com.br. Publicado em 25.02.2003, às 17:42h.

JORNAL DO BRASIL. 'Lula e Duhalde discutem Mercosul. Presidentes acertam priorizar área social'. 15.01.2003, p. A3.

JORNAL DO BRASIL. 'Temer diz que PMDB não quer cargos para apoiar reformas. Presidente do partido critica fisiologismo mas admite participar do governo’. 26.02.2003, p. A2.

O GLOBO. 'Hartung pede a Lula que libere verba para pagar funcionalismo. Governador diz que presidente prometeu dinheiro. Singer nega'. 03.01.2003, p. 5.

O GLOBO. 'Miro assume sem presença de Brizola. O ministério é que tomará as decisões políticas, não a Anatel, diz ele'. 03.01.2003, p. 5

O GLOBO ONLINE. 'Miro: 'Espero não decepcionar o meu partido, o PDT, o presidente Lula e o povo brasileiro"'. www.oglobo.com. Publicado em 02.01.2003, às 10:51h.

O GLOBO ONLINE. 'Hartung busca liberação de R\$ 300 milhões para pagar funcionalismo'. www.oglobo.com. Publicado em 02.01.2003, às 11:16h.

O GLOBO ONLINE. 'Lula repassa a Palocci pedidos do governador do Espírito Santo'. www.oglobo.com. Publicado em 02.01.2003, às 13:03h. 
O GLOBO ONLINE. 'Governador diz que 50\% das verbas enviadas para o ES foram desviados'. www.oglobo.com. Publicado em 02.01.2003, às 13:52h.

O GLOBO ONLINE. 'Integração da PF com polícias estaduais começa pelo Espírito Santo'. www.oglobo.com. Publicado em 02.01.2003, às 18:05h.

\section{Notas:}

(1) JB Online, 25.02.2003, 17:42h.

(2) Jornal do Brasil, 26.02.2003, p. A2.

(3) O Globo Online, 02.01.2003, 18:05h.

(4) O Globo Online, 02.01.2003, 11:16h.

(5) O Globo Online, 02.01.2003, 13:03h.

(6) O Globo Online, 02.01.2003, 13:52h.

(7) O Globo, 03.01.2003, p. 5.

(8) JB Online, 14.01.2003, 16:30h.

(9) Jornal do Brasil, 15.01.2003, p. A3.

(10) O Globo Online, 02.01.2003, 10:51h.

(11) O Globo, 03.01.2003, p. 5.

\section{Mini Currículo :}

Professor de Webjornalismo da Faculdade de Comunicação CCAA e pesquisador associado ao Laboratório de Pesquisa em Comunicação Política e Opinião (Doxa/IUPERJ). Mestre (2000) e doutor (2007) em Ciência Política pelo IUPERJ. E-mail: julianoborges@gmail.com 